\title{
STAKEHOLDER ENGAGEMENT FRAMEWORK
}

\author{
Paul Alan SMITH
}

\begin{abstract}
Stakeholder Engagement in a multinational organisation operating in an international environment encompasses the requirement to align stakeholders, to manage customers and industrial partners and to ensure that the organisations' internal and external communications reinforce that engagement. It is s C-level activity and must be coordinated and controlled within the organisation at the highest level. Otherwise, the organisation's ability to influence those, whose support it needs to secure or block in order to meet organisational objectives, will not be secured or neutralised. This engagement will differ depending upon the issue - a stakeholder could be supportive on one and against on another. Therefore, considered approach must be taken through coordinated implementation of issue specific stakeholder engagement action plans.
\end{abstract}

Keywords: Stakeholder Engagement, Customer Relationship Management, industrial relations, Stakeholder Engagement Action Plans, strategic plan, strategic outcomes, performance management.

\section{Introduction}

This paper describes how Stakeholder Engagement could be conducted in a complex IT organisation based on the actual experience in a complex multinational and international IT organisation within the security domain.

The term 'stakeholders' covers a broad body of people and groups from customers and suppliers to governance bodies and staffs. However, they are recognised because the organisation would like their support or neutrality on an issue for which the organisation seeks strategic and sometimes operational outcomes ${ }^{1}$ required for the successful delivery of the organisation's strategic objectives and targets.

This framework will outline: some Stakeholder Engagement principles; its relationship to communications; its dependence upon management, leadership and organisation performance; how and why it is focused towards predominantly strategic outcomes to achieve strategic effects; and the difference between the framework and a Stakeholder Engagement Action Plan (the execution of Stakeholder Engagement toward a specific issue). 


\section{What was Stakeholder Engagement in the organisation?}

Most staff engage with stakeholders during their duties and establish relationships with them. This is not Stakeholder Engagement but relationship building and is an essential precursor to successful Stakeholder Engagement. Stakeholder relationship building should be encouraged.

Stakeholder Engagement is primarily aimed at stakeholders outside the organisation. The bulk of engagement inside the organisation with the staff (an important stakeholder group) is operational or tactical in nature and is a general management activity falling to those appointed to lead and manage inside the organisation at every level.

\section{Who are our stakeholders?}

The principles and practices set out in this paper are intended to cover (but are not limited to) the organisation's public engagement with the following groups:

- The consumers of its products or services;

- The organisation's governance and policy bodies;

- National governments and other regulatory agencies;

- Industry; and

- Media, who may report on the organisation's decisions and activities.

\section{Stakeholder Engagement Principles}

Taking a principles based approach to stakeholder engagement activities enables the organisation to define principles that clarify the purpose of the organisation's engagement with stakeholders and guide how that engagement occurs.

Principles represent the organisation's ongoing commitment to work effectively with its stakeholders, learn from past stakeholder engagement experiences and continue to improve performance.

Principle 1: Stakeholder Engagement may require different approaches for different stakeholders or different objectives.

Principle 2: Stakeholders should be engaged early in an open and transparent manner, with sufficient time for them to have a genuine opportunity for input into a policy or programme decision by the organisation.

Principle 3: Stakeholder Engagement staff must use existing structures or relationships engaging stakeholders. Given the external focus of Stakeholder Engagement, it will draw upon stakeholder relationships held by organisation senior leaders, liaison teams, key staffs who engage with external stakeholders or those 
outside the organisation who by their experience, expertise or network can engage stakeholders on the organisation's behalf.

Principle 4: Stakeholder Engagement must be applied consistently across multiple communications paths for a sustained period to achieve its intended outcome and effect. Other mechanisms, such as routine management or communications, should be used to fix short term tactical problems.

Principle 5: Stakeholder Engagement must be conducted through a deliberate and coordinated Stakeholder Engagement Action Plan which is authorised at the highest level in the organisation and controlled by the Chief Strategy Officer.

Principle 6: Stakeholder Engagement objectives shall be prioritised at the highest level in the organisation and pursued in priority order commensurate with available resources.

Principle 7: Stakeholder Engagement staff shall provide information that is clear, accurate, relevant and timely, recognising the different communication needs and preferences of different stakeholders and that effective communication involves listening and talking.

Principle 8: Stakeholder Engagement staff shall be measuring and evaluating the organisation's engagement activities to understand what is effective, and improve the quality of organisation stakeholder engagement over time.

\section{Key Components of Stakeholder Engagement}

The key components of Stakeholder Engagement in an organisation are:

- Stakeholder Alignment;

- Customer Relationship Management;

- Industrial Engagement; and

- Communications.

\section{Stakeholder Alignment}

Stakeholder Alignment is about effectively engaging stakeholders on an issue in order to achieve a strategic outcome (sometimes an operational outcome) and associated strategic effect benefitting the organisation. It is targeted and deliberate. Alignment must be aimed at clarifying confusion, countering falsehoods, giving truth or fact and presenting arguments for stakeholders to make informed decisions. Stakeholder Alignment is transitory. It can influence stakeholders' on an issue but not shift their overall perceptions of the organisation. In most instances only organisational performance will do that. 


\begin{tabular}{|l|c|c|}
\hline \multirow{3}{*}{ STAKEHOLDER INFLUENCE ON AN ISSUE } \\
\hline \multirow{3}{*}{$\begin{array}{l}\text { INFLUENCE/ } \\
\text { POWER }\end{array}$} & KEEP SATISFIED & MANAGE CLOSELY \\
\cline { 2 - 3 } & $\mathrm{X}, \mathrm{Y}, \mathrm{Z}$ & $\mathrm{A}, \mathrm{B}, \mathrm{C}$ \\
\cline { 2 - 3 } & $\mathrm{D}, \mathrm{E}, \mathrm{F}$ & $\mathrm{V}, \mathrm{W}, \mathrm{X}$ \\
\hline \multicolumn{2}{|c|}{ MONITOR } & KEEP INFORMED \\
\hline \multicolumn{2}{|c|}{ STAKEHOLDER INTEREST IN THE ISSUE } \\
\hline
\end{tabular}

Figure 1: Determining the Stakeholder's interest in an issue against their influence or power helps determine how you plan to engage that stakeholder within the Stakeholder Engagement Plan for that issue.

The organisation therefore needs to identify a stakeholder's influence on an issue which will vary upon the stakeholder's interest on the issue and their influence or power within the environment overall (or perhaps on the issue itself). The Chief Strategy Officer will coordinate any Stakeholder Alignment activity once approved by the Chief Executive Officer.

\section{Customer Relationship Management}

Customer Relationship Management (CRM) is about developing requirements, honing products or services to meet customers' needs or addressing customers' issues on products and services. Stakeholder Alignment and CRM may address the same stakeholders on occasion but the message and purpose are very different. Stakeholder Alignment and CRM should both be transparent and accountable activities but CRM must clearly be in the limelight. Stakeholder Alignment and CRM must not be blurred in the organisation's actions to minimise them becoming blurred in the stakeholders' minds. If a customer believes the organisation is trying to influence their requirements, needs or choices by Stakeholder Alignment actions, CRM relationships will be undermined detrimentally. Stakeholder Alignment and CRM activities must therefore be tightly coordinated and, when appropriate, developed in parallel between Chief Strategy Officer and CRM staffs.

\section{Industry Engagement}

An enhanced industry engagement is essential to ensure that the organisation's mission to provide IT products and services in an efficient, effective and affordable manner, preferably taking a through-life approach.

A robust relationship with industry, coordinated by an Industry Relations (IR) office needs to be underpinned by suitable business models and partnering solutions, both 
in respect of procurement and non-procurement activities. The organisation must have a well-established approach to engaging with industry in procurement/ acquisition activities and non-procurement activities. Most nations (who may be the organisation's senior stakeholders) increasingly acknowledge that technological innovations and expertise from the private sector are crucial not only to deliver required capabilities but also to enable the organisation to achieve critical wider objectives, such as to counter cyber threats.

In this context a deepened dialogue with industry, including on executive level allowing for direct relations with individual companies and their leadership, is key to allow industry gain greater insight of the organisation's strategic objectives and visibility of the work carried out in the different phases of implementing them. This in turn will encourage industry to respond better and faster to capability and service needs and offer more innovative solutions.

IR should also progressively encompass direct engagement with small and medium enterprises and start-ups which are often the birthplace of innovation and can offer more agility as well as 'non-traditional' solutions and better value for money.

Developing a coherent IR approach should be based on a transparent and mutually beneficial dialogue with industry partners and improved coordination with industryrelated policy making stakeholders.

\section{Stakeholder Engagement and communications}

Like Stakeholder Engagement, effective, consistent and coordinated communication is essential to the success of the organisation's strategic objectives. Communication is integral to the execution of Stakeholder Engagement and includes the communications activities of Communications Office staff and the need for leadership at all levels in the organisation to participate in communicating effectively as line managers (internally) and ambassadors of the organisation (externally).

The communications team will focus between $70-80 \%$ of their effort on supporting external Stakeholder Engagement to achieve strategic outcomes and effects. Line manager communications will need to ensure the majority of internal engagement with staff is focused toward achieving the same ends as Stakeholder Engagement, ultimately the successful delivery of the organisation's strategic objectives and targets.

\section{Stakeholder Engagement and management, leadership and organisa- tional performance}

Leaders and managers can achieve a greater strategic outcome and effect than Stakeholder Engagement staff can alone, by providing vision and direction through clear 
communication with their staff. Appropriately cascaded strategic objectives and targets (perhaps through the performance management system) will reinforce these.

The organisation's performance is the major contributor to changing stakeholders' broad perceptions of the organisation. Stakeholder Engagement activities must therefore accurately reflect the positive aspects of organisation performance, taking 'conservative' positions. It definitely must not exaggerate performance.

Stakeholder Engagement does not need to and cannot target all stakeholders on every issue concurrently; just enough to secure the outcome and effect desired by the organisation. It must be focused at the right issue(s) and stakeholder(s) to achieve the best strategic outcome and effect for the organisation and be guided by the organisation's strategic objectives and targets.

Risk Management and Stakeholder Engagement should be carefully and regularly coordinated between Chief Strategy Officer and Risk Management staffs.

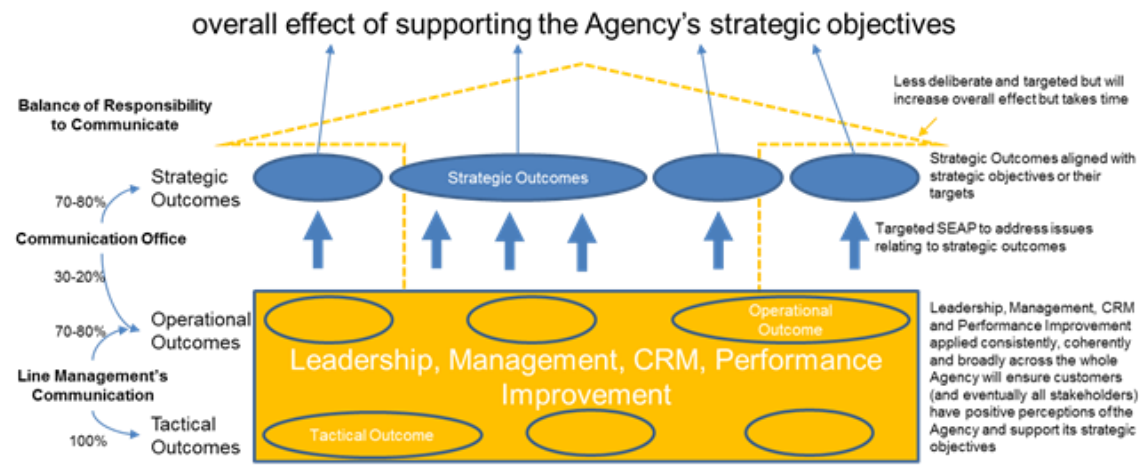

Figure 2: The diagrammatic representation of how an effect was achieved through stakeholder engagement in a multinational Agency.

\section{Five Step Issue Analysis}

Stakeholder Engagement requires careful analysis of the issue, which by default requires an understanding of the stakeholder's stance on that issue. This process can be conducted in five steps.

\section{Step One}

When considering the issue, some stakeholders will also be customers but some customers will not have a stake in the issue - these do not need to be engaged on the issue through Stakeholder Engagement. Those that are both customers and stakehold- 


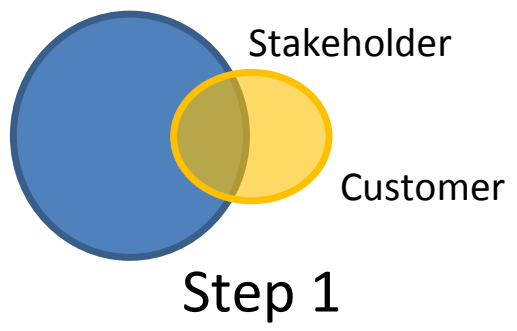

ers need to be considered carefully so not to damage CRM activity with Stakeholder Engagement activity.

\section{Step Two}

Stakeholders with an interest in an issue are not all equal. It is necessary to ensure how significant their interest and its consequences for your engagement are. Some stakeholders will be key to the outcome you seek from the engagement, some influential but not key and some just interested, though neither key nor influential.

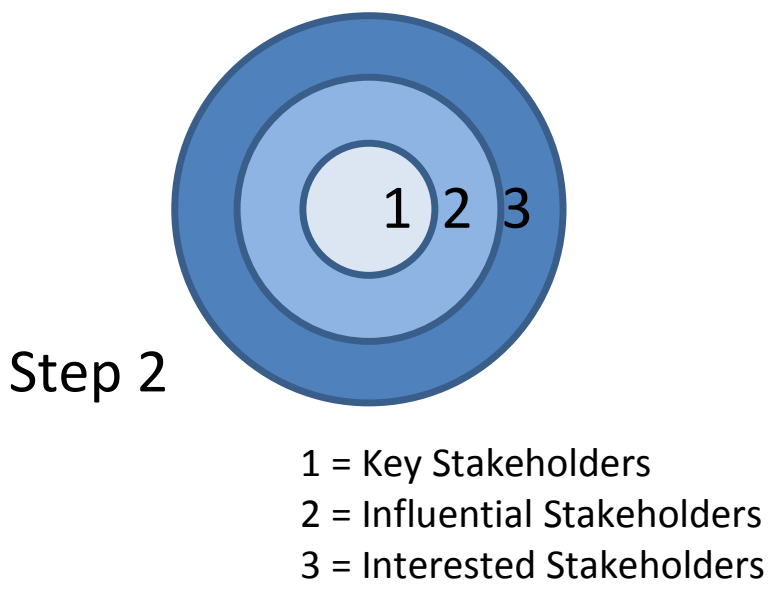

\section{Step Three}

The stakeholders identified will have some questions on the issue which will need to be answered when they are engaged. Some of these may be generic and so could be built into the general briefings to stakeholders; others will be specific to that stakeholder and will need to be communicated individually to that stakeholder. Similarly, the organisation will have some questions on the issue which will need to be addressed especially if internal communications are required or if support within the organisation is required to pursue an issue - even though it may have been sanctioned at the highest level within the organisation. 


\section{Step 3:}

- Stakeholder Questions

- Organisation Questions

\section{Step Four}

The engagement of the stakeholder has a purpose within the bounds of the issue. It could be to ensure they remain satisfied and supportive (see quadrant " 1 " in the figure below), in which case they just require monitoring throughout the engagement to confirm that they remain so - perhaps focusing more on those whose support really needs to be secured as opposed to those whose influence or power on the issue is lower and just need a flexible and optimal approach. There may be some lower influence / power stakeholders (quadrant "2") who you would like to be more influential on an issue; Stakeholder Engagement with other stakeholders could secure this increase. Similarly, provision of information to them could increase their relative influence. There may be some powerful, interested stakeholders (quadrant "3") whose relative position on the issue may not be in the interests of the organisation to secure a positive outcome in the issue at hand. One must be flexible here and accept the optimum outcome by the Stakeholder Engagement effort. However, again, engagement with other stakeholders or the increase or withholding of information on that issue could reduce their relative interest on the issue.

\section{Step Five}

The final step is especially important when the stakeholder cannot easily be engaged through Stakeholder Engagement. This is because a stakeholder is rarely an organisation in the environment, but an individual within that organisation which makes the decision or holds the power to do so. When this is the case, detailed targeting analysis needs to be conducted to identify how to get to the stakeholder. This could require engagement of a different style because the act of engagement is, in a way, being sub-contracted and so more difficult to ensure a successful outcome.

Often the stakeholder is surrounded by advisors whose advice will need to be influenced either through direct engagement or through second parties. Occasionally, second parties can access the stakeholder directly (by passing advisors) or engage another party (a star) with direct bypassing access to the stakeholder. This is illustrated on the second figure on the next page. 

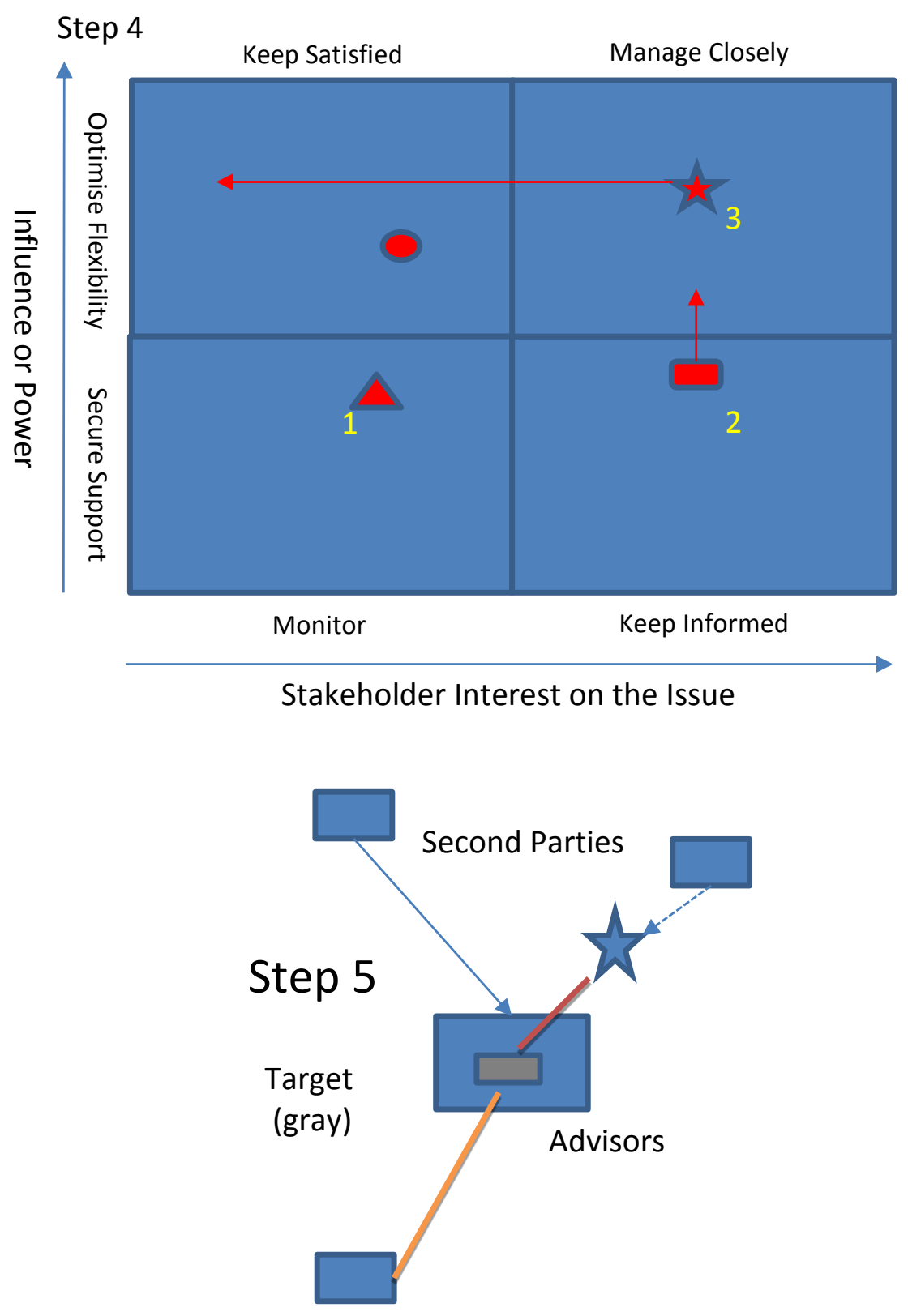


\section{The Stakeholder Framework and a Stakeholder Engagement Action Plan}

The Stakeholder Engagement Action Plan (SEAP) describes how a stakeholder engagement will be carried out against a particular stakeholder or set of stakeholders in order to engage them on an issue or topic that is so important, that its outcome has a strategic effect on the organisation. The SEAP, not the framework, delivers specific effects that support the execution of the organisation's strategic plan.

The SEAP is a deliberate campaign. It will ensure the efficient use of time and resources available to senior executives. It must be authorised and controlled at the highest level in the organisation. It will identify the issue, the strategic outcome and associated strategic effect desired, what stakeholder(s) need to be engaged, how that will be done, when, by who and where. It will identify the risks and constraints. Finally, how and when its outcome will be assessed.

On some issues, it may not be possible to engage the important stakeholder directly. In such case a targeting exercise will be required.

\section{Conclusion}

Stakeholder Engagement must be controlled at the highest level in an organisation, defined in a Framework and guided by carefully considered Principles. Engagement of a Stakeholder is about engagement on an issue: a stakeholder will not have the same position on every issue; they will not be supportive on every issue facing the organization. Their position on that issue, and the organisation's response to align that stakeholder's position, need to be carefully judged and coordinated through a Stakeholder Engagement Action Plan (SEAP): this response could mean blocking a key stakeholder's position in order to ensure the organisation can successfully implement a strategic or operational outcome. Analysis of where stakeholders position on issues focuses the engagement effort and step 5 of the Issue Analysis helps find routes to difficult to access stakeholders.

A customer is also a stakeholder but activities of customer relationship management staffs and stakeholder engagement staffs must be coordinated so as not to confuse the stakeholder: when a Stakeholder Engagement staffer deals with a stakeholder who is also a customer, that customer must not believe the engagement is to sell a product or service. Stakeholder Engagement is a wholly different type of engagement to Customer Engagement and often to secure support or sound out the stakeholder-customer's position on an issue - perhaps to block it.

Communication is a critical tool of Stakeholder Engagement - ideally the organisation's communications group should report to the Chief Strategy Officer. SEAP have an integral communications plan developed in support and need to be pitched to 
deliver a strategic outcome respecting the time required for strategic communications to have an effect. The best SEAP (and corresponding communications plans) should be pitched eight months ahead and over time narrow in on the target(s) of the SEAP so that when the issue comes to a decision point, the outcome of the decision on that issue is already foretold.

\section{Acknowledgement}

Nadja Elfertasi and Michal Olejarnik who together helped build and implement a comprehensive Stakeholder Engagement activity within a multinational international organisation operating in the defence sector.

\section{Notes:}

${ }^{1}$ Strategic Outcome - one that requires a team effort from within the organisation's senior leadership to achieve a strategic effect: centrally coordinated, planned and aligned with strategic objectives and targets. Operational Outcome - one that requires Director/Head led action (often aligned with their functional responsibilities) which is coordinated by that Director/Head as they see fit: implemented by the Director/Head's senior management. Tactical Outcome - one that occurs within a Directorate and is senior management led (often aligned with their Director's targets or Goals \& Objectives) and is executed by the leaders within the Directorate.

\footnotetext{
About the author

Paul Alan SMITH is British and an Executive Coach and former Chief Strategy Officer of a multinational IT organisation supporting a major international organisation operating at the heart of Western defence and security.
} 